\title{
On tasty colours and colourful tastes? Assessing, explaining, and utilizing crossmodal correspondences between colours and basic tastes
}

\author{
Charles Spence ${ }^{1,7^{*}}$, Xiaoang Wan ${ }^{2}$, Andy Woods ${ }^{1,3}$, Carlos Velasco ${ }^{1}$, Jialin Deng ${ }^{4}$, Jozef Youssef ${ }^{5}$ and Ophelia Deroy ${ }^{6}$
}

\begin{abstract}
Can basic tastes, such as sweet, sour, bitter, salty, and possibly also umami, be conveyed by means of colour? If so, how should we understand the relationship between colours and tastes: Is it universal or relative, innate or acquired, unidirectional or bidirectional? Here, we review the growing body of scientific research showing that people systematically associate specific colours with particular tastes. We highlight how these widely shared bidirectional crossmodal correspondences generalize across cultures and stress their difference from synaesthesia (with which they are often confused). The various explanations that have been put forward to account for such crossmodal mappings are then critically evaluated. Finally, we go on to look at some of the innovative ways in which chefs, culinary artists, designers, and marketers are taking — or could potentially push further - the latest insights from research in this area as inspiration for their own creative endeavours.
\end{abstract}

Keywords: Colour, Basic tastes, Crossmodal correspondences, Design, Gastronomy, Synaesthesia

"Colour clearly conveys to the brain what taste is to be expected" ([63], p. 86).

"Sight by itself informs us only of colors and forms [and that] ... No one can pretend that the images of sight are determinate in reference to taste." Peirce [42]

\section{Review \\ Introduction}

The idea that the four or five basic tastes-bitter, sweet, sour, salty, and possibly also umami-are in some way associated with particular colours is one that has widespread currency. The idea surfaces in many places, from the fiction of Borges $[2]^{1}$ through to innovative marketing campaigns such as the one orchestrated on behalf of Boss, a Belgian paint manufacturer (see [64]). ${ }^{2}$ But is

\footnotetext{
* Correspondence: charles.spence@psy.ox.ac.uk

'Crossmodal Research Laboratory, Oxford University, Oxford, UK

7Department of Experimental Psychology, University of Oxford, Oxford OX1 3UD, UK

Full list of author information is available at the end of the article
}

there something more to the idea of mapping basic tastes and colours than an interesting aesthetic endeavour?

Traditionally, the mapping of colour onto taste, or vice versa, has been based on the intuitions of the creative or designer involved, or else on the crossmodal associations apparently experienced by a few synaesthetes for whom the experience of taste comes with a conscious experience of colour-what is known as a concurrent (e.g. [23]). The key question here, though, is whether we can ever be sure that the mappings that have been suggested by writers and designers really do appeal to a wider audience? An intriguing body of empirical research conducted over the last three decades now shows that all of us (no matter whether we are synaesthetes or not) do indeed match basic tastes to colours in ways that are far from arbitrary-in the sense of being regular across individuals and consistent over time [24, 28, 35, 65, 71].

What is especially surprising here is that the basic tastes are not uniquely associated with a particular food source: That is, the colour that they are associated with cannot simply be traced back to the colour of a particular fruit, vegetable, or foodstuff. The colour red for 
instance, which is commonly associated with sweetness, is not just characteristic of sweet ingredients (think here only of red meat, or red chili) and it is not obvious that sweetness is more often present in red foodstuffs than yellow, white, brown, or orange foods. This aspect of the correspondences between colours and tastes makes them intriguingly different, then, from the association between the smell of lemon and, for example, the colour yellow (see [11]). In this respect, the pairings between tastes and colours do not count as associations between features or properties of the same kind of object (what are commonly referred to as semantic associations) but more as crossmodal correspondences, which are defined as matchings between apparently unrelated sensory features and dimensions (see $[13,54])$. To be clear, the term crossmodal correspondences refers to the associations that people make between dimensions of experience that cannot be explained simply by pointing to a common source (e.g. as when we match a barking sound with the picture of a dog, or more pertinent here, the smell of a lemon with the colour yellow; see [32, 41]).

Characterizing the relation between basic tastes and colour as a kind of crossmodal correspondence does not presuppose that a single relation is at stake. Although tastes are often described as being, in some sense, 'basic', they will also have a perceived intensity and an associated hedonic valence once in the mouth [3]. Likewise, colours are also analysed and described in terms of different dimensions, such as their hue, saturation, and brightness. In this respect, then, there might well be different correspondences, or even a complex network of correspondences, underlying the matching of any specific colour with any particular taste. So, for instance, one such mapping might exist between more intense tastes and more intense (i.e. brighter and more saturated) colours (see $[54,55])$.

\section{Outline}

In the present article, we start by reviewing the scientific literature on crossmodal correspondences between taste (in the gustatory sense) and colour that has been published to date. One can think of these correspondences in terms of Koch and Koch's [28] notion of "preconceptions of taste based on color" (the "Crossmodal correspondences between colour and taste words: the empirical evidence" section). The bi-directionality of these robust and widespread mappings are highlighted. Indeed, this is one of the features that helps to distinguish the correspondences from those rare individuals, known as synaesthetes (with chromatic gustation), who experience colour on tasting certain foods (Synaesthesia vs. crossmodal correspondences). Having established the robustness, and cross-cultural generality of these crossmodal associations (see [71]), and having distinguished them from synaesthesia, we then go on to review the various theories that have been put forward over the years in order to account for such 'potentially surprising' links between the senses (Where do crossmodal correspondences between colour and taste come from?).

The latest scientific insights concerning such crossmodal correspondences are now starting to be gleaned from large-scale online studies conducted in several countries simultaneously (see [71], for one recent example). The results of such studies have started to inspire and/or constrain gastronomic and artistic creations. The crucial shift that is now beginning to occur here is from designs that were traditionally based solely on the intuitions of the creative to designs that have been inspired by, and often tested against, the mean responses of a representative group of individuals. In the "Utilizing the crossmodal correspondence between colour and taste" section, we will see how the latest evidence on colourtaste matching has been incorporated into a variety of real-world situations, varying in terms of their relation to food (the most natural place for the association to surface). Specifically, we provide examples from the coloured amuse bouches $[20]^{3}$ recently introduced by one chef, through to colourful plateware designs [58]. We end up with a case study concerning the use of colour-taste correspondences in the marketing of paint. We evaluate how well the first two of these innovative design solutions do in terms of capturing the crossmodal mappings between colour and taste using both the in-person (or offline), and online, testing of people's attitudes.

\section{Crossmodal correspondences between colour and taste words: the empirical evidence}

Over the last three decades, a number of researchers have assessed the colours that people tend to match to the basic tastes, either by asking them which colour go best with a certain taste, or vice versa. In one of the first studies of its kind to have been conducted in this area, O'Mahony [35] had 51 students at the University of California, Davis pick 1 of 12 colours (comprising black, blue, brown, gold, green, yellow, grey, orange, red, silver, violet, and white) to match each of the four basic taste words (bitter, salty, sour, and sweet). This task was performed three times at 2-week intervals. O'Mahony reported the number of participants who gave the same colour response on all three of the occasions on which they were tested (see Table 1). The greatest consistency of responding was in response to the sweet taste when matched with the colour red (with 7 of the 51 participants choosing this colour every time), yellow for sour (10/51), white for salty $(15 / 51)$. There was also a weaker, but still significant, tendency for participants to consistently pick green and black for bitter (4 and 3/51, respectively). 
Table 1 Number of participants $(N=51)$ who chose the same colour (from a choice of 12 colours) to match each of the four basic tastes on three separate occasions

\begin{tabular}{lllllllllllll}
\hline & Red & Orange & Yellow & Green & Blue & Violet & Brown & Black & White & Grey & Silver & Gold \\
\hline Sweet & 7 & 3 & 2 & 1 & 1 & 1 & 0 & 0 & 2 & 0 & 0 & 0 \\
Sour & 0 & 2 & 10 & 3 & 0 & 0 & 0 & 0 & 1 & 0 & 0 & 0 \\
Salty & 0 & 0 & 1 & 0 & 0 & 0 & 0 & 0 & 15 & 1 & 0 & 0 \\
Bitter & 0 & 0 & 0 & 4 & 1 & 0 & 2 & 3 & 0 & 2 & 0 & 0 \\
\hline
\end{tabular}

Note that any value greater than 0.0295 in the table indicates that the regularity with which the colour was chosen by the participant was significantly greater than that expected by chance. (Data taken from [35], Table 1)

O'Mahony [35] also had his participants match the days of the week and seven US states to both colours and tastes. Friday and Saturday are unambiguously associated with sweet, as are the states of California, Florida, and Oregon. O'Mahony's interest in carrying out this line of research related to the status of 'sweet', 'sour', 'bitter', and 'sour' as, in some sense, 'primary', tastes. More specifically, O'Mahony wanted to know whether consistent responses/associations could be generated in response to the basic taste words (without participants simply referring back to the terms bitter, sweet, salty, and sour).

In her 1999 book, whose title translates as How colour works, German sociologist Eva Heller described the results of a study in which she had close to 2000 Germans (from all walks of life) assign colours to the four main tastes. Heller reports that green and yellow were predominantly associated with sour whereas pink, orange, and red were associated with sweet. On the other hand, white, grey, and blue led people to expect a salty taste, and violet, black, and brown were associated with a bitter taste (see Table 2). In contrast to O'Mahony [35],
Heller's motivation in carrying out this research related to a more general interest in the psychological and symbolic meaning of colour.

In 2003, Koch and Koch reported a small scale study ( $N=45$ university students studying business) assessing the crossmodal correspondences between the 4 basic tastes and 10 colours (black, blue, grey, brown, green, orange, purple, red, white, and yellow). Participants rated how strongly each taste (identified by a taste word) was related to a given colour term using a 10-point scale. Thus, each participant had to complete a total of 40 questions of the following form: "On a scale from 1 to 10 with 10 being the most sweet, how sweet is the color red?" Higher scores $(7-10)$ were taken to indicate a positive association, whereas lower scores (1-3) were taken to indicate a negative association. Intermediate scores (4-6) were taken to indicate some weak relationship between colour and taste. Analysis of the results revealed significant crossmodal associations between both red and orange on the one hand and a sweet taste on the other. Associations were also documented between both green and yellow and sour, as well as between

Table 2 Summary of results of published studies showing crossmodal correspondences between colours and basic tastes

\begin{tabular}{|c|c|c|c|c|c|}
\hline Study & O'Mahony [35] & Heller [24] & Koch and Koch [28] & Tomasik-Krótki and Strojny [65] & Wan et al. [71] \\
\hline Number of participants & 51 & $\approx 2,000$ & 45 & 519 & 452 \\
\hline Origin of participants & USA (CA) & Germany & USA (OR) & 17 countries & 4 countries \\
\hline Type of participants & University students & Cross-section of the public & Students & High school and university students & Internet recruits \\
\hline Black & (Bitter) & Bitter & (Bitter) & - & Bitter \\
\hline Blue & & Salty & & Salty & \\
\hline Green & (Bitter) & Sour & Sour & Sour (bitter) & Sour \\
\hline Orange & & Sweet & Sweet & Sweet & \\
\hline Pink & - & Sweet & - & - & Sweet \\
\hline Red & Sweet & Sweet & Sweet & Sweet & \\
\hline Violet & & Bitter & & Bitter/umami & - \\
\hline White & Salty & Salty & Salty & - & Salty \\
\hline Yellow & Sour & Sour & Sour & Sour & \\
\hline Brown & & Bitter & & - & \\
\hline Grey & & Salty & - & - & \\
\hline
\end{tabular}

The participants in these studies were either given the names of one of the four or five basic tastes and had to pick a matching colour or else rate how well (or badly) the colour matched a given taste. The strongest crossmodal correspondences are shown, while weaker correspondences appear in brackets Note: Dashes denote the fact that this colour was not tested in this study. Note also that not all of the colour options are shown for every study 
white and salty (see Table 2). Interestingly, 17 of the 45 participants tested by Koch and Koch indicated a strong relationship between black and bitter as well (the responses of a further 23 participants indicated no relationship, while the responses of a further 5 participants indicated a moderate relationship). Interestingly, the only colours not to show any positive colour-taste associations were blue, purple, and grey.

In 2008, Tomasik-Krótki and Strojny had their participants (a convenience sample of more than 500 individuals from 17 different countries, covering a number of continents) via questionnaire: "how they link the colours, red, orange, yellow, green, blue, and violet to the tastes bitter, sweet, umami, sour and salty" ([65], p. 253). The wording of the article itself is a little ambiguous as to what exactly the participants had to do. ${ }^{4}$ That said, crossmodal associations between red and orange with sweet, yellow and green with sour, blue with salty, and violet with bitter and umami were documented (see Table 2). A subset of the participants in this study also associated a bitter taste with the colour green. The researchers' interest in carrying out this study was different again from that in the other previous studies reported in this section. Tomasik-Krótki and Strojny were specifically interested in trying to establish any crossmodal associations between colours and both tastes and odours on the other. These researchers created units of taste (mnians) and odour (fooys) and a permutation system that would allow for the standardized translation of one sensory impression into another across the senses.

Finally, and most recently, Wan et al. [71] conducted an online study in which they assessed the crossmodal correspondence between the five basic tastes and colours in four groups of participants from mainland China, India, Malaysia, and the USA. The participants were presented with a random sequence of 11 colour patches (black, blue brown, green, grey, orange, pink, purple, red, white, and yellow). One of these colour patches appeared in the centre of the screen at the start of each trial. The participants had to click and drag the colour patch onto one corner of a taste pentagon centred on the colour patch at the start of the trial (see Fig. 1).

The results revealed that the black colour patch was associated with bitterness, green with sourness, pink with sweetness, and white with a salty taste (see Fig. 2). Note how these results are broadly consistent with those reported in the other studies that have been documented in this section (see Table 2). However, beyond the introduction of a novel internet-based methodology for testing crossmodal correspondences between colour and taste, a second aim of Wan et al.'s study was to more systematically look at any cross-cultural differences in colour-

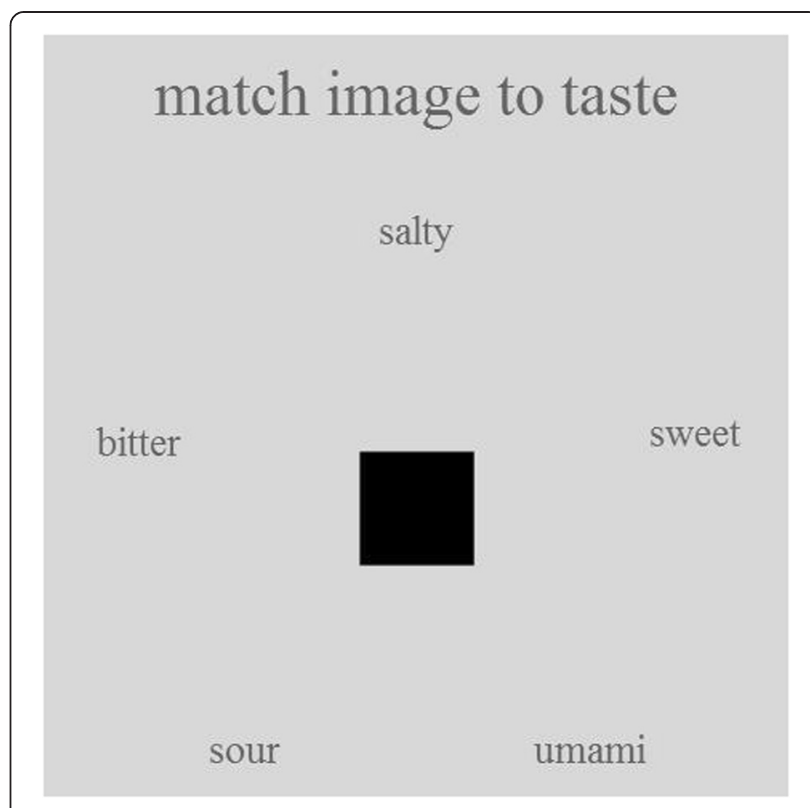

Fig. 1 Screen shot from Wan et al.'s [71] study assessing the crossmodal correspondence between colour and taste. Participants had to drag the colour patch to the matching taste

taste correspondences (cf. [4] for a cross-cultural study of shape-taste correspondences). The cross-cultural similarities/differences in the patterns of responding that were observed are highlighted in Fig. 3. While the results across the four different countries are globally similar, some important local cultural differences were also observed. So, for example, if one looks at the number of participants who matched each of the tastes with the white colour patch, then visual inspection of the results highlights the fact that the Chinese participants were much less likely to pick salt as the most appropriate taste than were those participants from any of the other three countries tested in their study.

One of the other questions that Wan et al. [71] asked their participants concerned how confident they were in terms of the colours that they chose for each of the tastes (following [29]). ${ }^{5}$ Specifically, they had to report how confident they were that other people would respond in the same way that they had. Responses were made by indicating a point on a 5-point horizontal scale with the following options, arranged from left to right: Very unconfident, unconfident, uncertain, confident, and very confident. Analysis of the data (see Fig. 4) revealed that the participants were not especially confident in matching colours to tastes (the mean rating was 3.62 when the 5 confidence ratings were assigned values of 1 , $2,3,4$, and 5 , respectively). These results are particularly interesting in that they show that individually, people are not all that confident that the crossmodal mappings between colours and tastes are shared. ${ }^{6}$ Notice how it is 

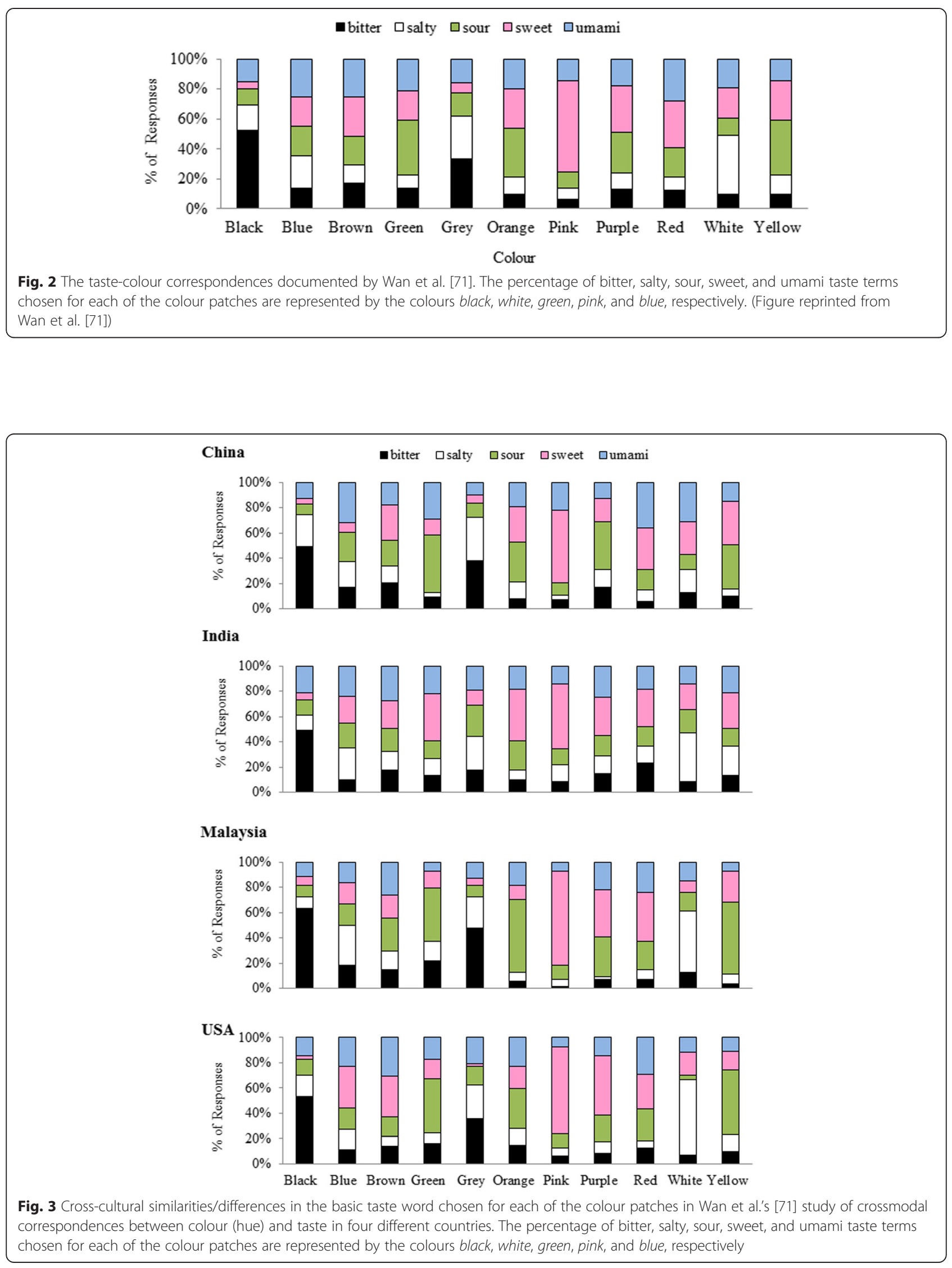

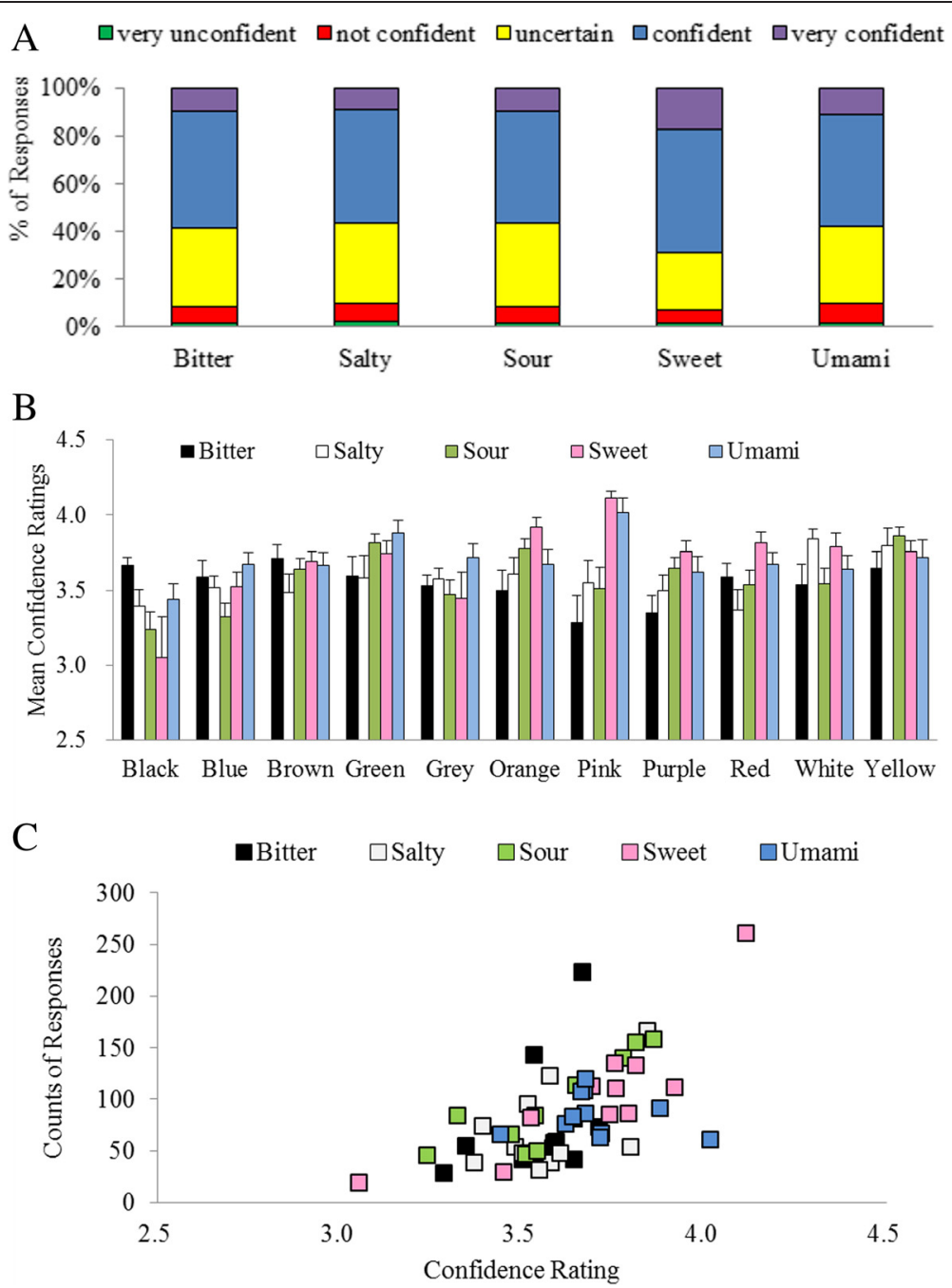

Fig. 4 a Confidence ratings of all participants (i.e. collapsing across nationality) when they chose each taste as the best match for a specific colour in Wan et al.'s [71] study. b Mean confidence ratings for the correspondence between each colour and each taste in Wan et al.'s [71] study. Error bars represent the standard errors of the means. c Scatterplot showing the positive correlation between the mean average rating and the chosen counts of each taste term for each colour in Wan et al.'s [71] study

only when the data from the participants is combined that clear answers (that is, a consensual response) start to emerge. Given such a pattern of results, it can be argued that chefs and food companies alike would benefit from large-scale online studies (such as reported by [71]) when choosing their crossmodal matches.

\section{Limitations and considerations}

Taken together, the results of the five studies reported in this section tell a remarkably consistent story: The colour black (and possibly also purple/violet) is widely associated with bitter, salty is white, or possibly blue, sour is yellow and possibly green, and sweet is pink and/or red (see Table 2). Moreover, this consensus was reached despite the fact that dramatically different sample sizes were used and the various studies were conducted in different countries in different decades with very different aims by the researchers concerned. It is worth pausing to consider the following two issues. As shown in Table 2, the studies vary regarding the participants who were tested. As is all too frequently the case in psychology research, O'Mahony [35] and Koch and Koch [28] only tested university students. The sample tested in these studies therefore likely qualify as biased toward WEIRD individuals who, following Henrich et al. [25] acronym, represent the small minority of people leaving in Western, Educated, Industrialized, Rich, and Democratic countries. By contrast, the other three (larger) studies $[24,65,71]$ were all recruited from a broader demographic base. Nevertheless, the results of these five studies look broadly similar, thus implying that the WEIRDo's in this case were not so strange after all, or perhaps, more 
reassuringly, that such crossmodal correspondences transcend education and cultural background.

Note also how more than three decades separate the first and last of the five studies reported in this section. In that time, people's associations with certain food colours have undoubtedly changed. One illustration of this comes from the various blue foods that one finds in the supermarket nowadays: Rolling the clocks back to the 1970s and 1980s, many researchers used to advise us that blue foods were an absolute no-no in the marketplace and would never succeed. For example, according to Watson ([72], pp. 66-67): "We have a deep-seated dislike of blue foods. Take a trip through a supermarket and see how many blue ones you can find. They are rare in nature and equally rare in our artificial hunting grounds. No sweet manufacturer ever successfully marketed a blue confection, and no blue soft drink or ice cream appeared on sale for very long." Nowadays, by contrast, blue drinks are reasonably common in the drinks aisles (see [19, 49]). Interestingly, though, despite these historical changes, visual inspection of Table 2 certainly does not reveal much in the way of obvious changes or trends in colour-taste matching over the decades. In other words, the crossmodal correspondences between colours (hues) and basic tastes appear to have remained fairly consistent over the last three decades. This might again hint at the important difference between this kind of crossmodal correspondence and the semantic (conceptual) associations that we all learn between the colours and tastes of specific foods or food brands. Careful inspection of Table 2 might, though, suggest another explanation for the choice of the colour (or colours) that is (are) associated with a given basic taste. As the range of alternative colours (hues) that the participants in these various studies have been offered varies, the possibility remains that a given choice is simply the least bad of the options that was made available to the participants. One can see, for example, that pink was always chosen as a match for a sweet taste when it was one of the response options. Unfortunately, however, this option was only available to the participants in two of the five studies shown in Table 2, namely Heller [24] and Wan et al. [71].

Finally, the fact that taste words, rather than actual tastants, were used in all of the studies that have been conducted to date could also be considered as something of a limitation (cf. [53]). One specific problem with using taste words is that many participants (especially those in the West) are unsure of what the term 'umami' actually refers to. ${ }^{7}$ That said, having participants pick the colours that would match the four or five pure tastants in solution could introduce its own difficulties, as people sometimes confuse the identity of pure tastants when presented in solution. So, for example, people sometimes/often identify sour solutions as bitter (e.g.
[36]). Hence, on balance, and considering the ease of use of taste words in online research, our preference (and that of the other researchers whose work has been reviewed in this section) would still be to go with taste words rather than actual tastants. ${ }^{8}$

Now it is important to note that we, and prior researchers, have somewhat simplified the problem by choosing to focus only on the four or five most common of the basic tastes. Over recent years, there has been a growth of evidence to suggest that there might be a number of other basic tastes (some suggest as many as 23 or more, see [62]) including fatty acid taste and metallic. Anyone wanting to assess the colour matches for these less familiar tastes may well need to revert to delivering actual tastants.

And on the flip side, one could, of course, also question the appropriateness of using colour names rather than actual colours, as occurred in all but one of the studies summarized in Table 2. Bear in mind here only the potential difficulty associated with knowing exactly how coloured stimuli appear on screen, given the vagaries of different monitor characteristics when one wants to conduct one's studies online. Nevertheless, despite these minor concerns, the main point to draw from the summary of the results of those studies reviewed in this section is just how consistent colour-taste mappings are, across culture, across time, and across different experimental paradigms.

\section{Synaesthesia vs. crossmodal correspondences}

Does the research that has been reviewed above demonstrate that we can all, in some sense 'taste colours'? Some researchers and designers have certainly wanted to conclude that the tendency to associate colours with tastes reflects a kind of universal synaesthesia (e.g. [45]). Early on, Déjerine [10] coined the term chromatic gustation (or la gustation colorée) to describe those individuals who reported experiencing certain colours (concurrents) on tasting specific foods (the inducing stimulus). ${ }^{9}$ However, here, it is important to note that while intriguing, it turns out that such cases of chromatic gustation are, in fact, extremely rare (see $[6,15]$ for case studies, and see [9] for a summary of different types of synaesthesia).

Some case studies of chromatic gustation are very striking. For instance, the synaesthete "S", who was thoroughly tested a little over a century ago by Downey [15] experienced very vivid colour concurrents that could last for up to 10 min. ${ }^{10}$ These colour concurrents were localized to the mouth and tended to be stronger when $\mathrm{S}$ closed his eyes (see [15], p. 528). Downey carefully controlled stimulus delivery so we can be certain that it really was the tastes (in the gustatory sense) of the stimuli that were the inducer in this case. ${ }^{11}$ Another interesting finding was that while colour concurrents were 
triggered by pure tastants, they were not elicited by food-related odours. ${ }^{12}$

Crucially, though, the relationship between the inducing taste and the concurrent colour in chromatic gustation synaesthesia is unidirectional [13]. That is, in every case that we are aware of, it was the taste (or flavour) of a food or drink that induced a particular colour concurrent, and not vice versa. By contrast, as reviewed in the "Crossmodal correspondences between colour and taste words: the empirical evidence" section, people (all nonsynaesthetes as far as we are aware) can both pick colours for tastes, and match tastes to colours: In other words, the crossmodal correspondence between taste and colour appears to be bi-directional, hence illustrating one of the key differences between these widespread crossmodal correspondences and synaesthesia. Another key difference between these two phenomena is that the synaesthete actually sees the colour on tasting the food, whereas the average non-synaesthetic observer in the studies reported in the "Crossmodal correspondences between colour and taste words: the empirical evidence" section merely expects, or guesses, the association between colour and taste without actually experiencing the colour itself on thinking about a particular taste, or on being given a specific taste. Finally, the inducer-concurrent associations that are experienced by synaesthetes tend to be fixed over a lifetime (or at least remain fixed for as long as the synaesthete can remember). By contrast, novel crossmodal correspondences can, in certain cases at least, be learnt over a surprisingly small number of exposures to a new statistical regularity in the environment or psychophysics laboratory [17].

The existence of chromatic gustation synaesthesia and, more generally, the unusual experiences reported by representatives of the roughly $4 \%$ of the population who count as synaesthetes have often been used as inspiration in the fields of art and design (e.g. [23]). Here, though, we wish to argue that the idiosyncratic nature of the synaesthete's concurrents (this, in fact, being a defining feature of the condition, at least according to some researchers; see [21]) means that it is going to be exceedingly difficult to take the concurrent colours that are experienced by a chromatic gustation synaesthete as a useful source of information when it comes to trying to generate specific expectations of taste based on colour that work with the public at large. That said, it should not come as any surprise if it turns out that certain of the taste inducer-colour concurrent mappings reported in those synaesthetes with chromatic gustation end-up matching, at least in a subset of cases, the taste-colour correspondences reported by non-synaesthetes: S, for instance, reported seeing green on being given a sour taste [15]. After all, the combination of 10 colours and 5 basic tastes is not so large that some synaesthetes will not present one of the 6-8 associations found in nonsynaesthetes by chance. It would also not be all that surprising if (in fact, one might expect that) the matchings learned by individual synaesthetes are constrained by the highly regular correspondences that are present in every one of us (see [14]).

\section{Where do crossmodal correspondences between colour and taste come from?}

Having established the robustness of the crossmodal correspondences that exist between colours and basic tastes, and having shown that the same mappings appear to hold across a number of distinct cultural groups, the most obvious next question is to wonder where these mappings come from, if not reflecting an example of synaesthesia. Over the years, at least five main classes of explanation have been put forward in order to explain crossmodal correspondences (see $[12,54]$ ) and seem relevant to explaining the taste-colour case (and note here that these various explanations need not be considered as mutually exclusive):

1) The structural account: According to this account, certain correspondences may have a structural origin, meaning that they reflect the inherent structural, wiring, or processing constraints of the human brain (that is, they are not learnt). One example of such a structural correspondence might, for example, be the mapping of more intense stimuli across sensory modalities, given the similar way in which stimulus intensity is coded across the senses (namely as an increase in neural firing; see $[54,60]){ }^{13}$

2) The statistical account: According to a second account (one with perhaps the most explanatory power), crossmodal correspondences may simply reflect the internalization (in the observer) of the statistical regularities of the environment (e.g. [75]). So, for example, the fact that sounds having a higher pitch tend to be localized higher in space is a result of the fact that small objects tend (on average) to make it further from the ground, combined with the filtering properties of the outer ear (see [40]). Relevant here, developmental data shows that already, by 6 months of age, the infant can internalize the relationship between the colour of the cup and the taste of the contents ([46]; see also [30]).

3) Semantic (or linguistic) correspondences: The third popular account is the semantic (or linguistic) one [69] and is based on the observation that we often use the same descriptors for qualitatively different sensory impressions. According to the proponents of this thesis, the common use of the same terms might provide the basis for linking sensations across 
the senses [33]. ${ }^{14}$ It is certainly possible that the semantic/linguistic account may build on the statistical regularities of the environment-so, for example, the reason why people associate sounds having a higher frequency with the word 'high' may be because such sounds are, statistically speaking, more likely to come from higher in space (see [40]).

4) Use of the availability heuristic: A fourth potential account for what may be going on in colour-taste matching studies is that the participants involved might simply be using the availability heuristic (e.g. [27, 43]). In other words, the participants in the various studies reported in the "Crossmodal correspondences between colour and taste words: the empirical evidence" section might have been judging as most appropriate for a given taste, those food colours that they could most easily and immediately bring to mind as exemplifying a given taste. So, for example, when asked what colour goes with a sour taste, those who thought of (in the sense either of creating a mental image or merely activating the concept) a lemon end up saying yellow, whereas those who bring to mind a lime choose green instead. Indeed, none of the studies assessing the crossmodal correspondence between taste and colour reported in the "Crossmodal correspondences between colour and taste words: the empirical evidence" section controlled for mental imagery [56]. ${ }^{15}$

5) Affective correspondences: According to the affective mediation account, people may simply want to match pairs of stimuli if they happen to evoke the same feeling or emotion or are known to be associated with the same affective state (e.g. $[5,39,66,68])$. Relevant here is the longstanding literature showing that colours are associated with emotions [37, 38, 52]. Similarly, hedonic responses are also associated with/triggered by the presentation of basic tastes [3, 44, 47, 59]. Hence, given what is already known, the participants in the studies reported in the "Crossmodal correspondences between colour and taste words: the empirical evidence" section could, presumably, potentially be matching based on the hedonic value or emotion associated with each individual stimulus. No one has, though, as least not as far as we are aware, proposed an affective mediation account specifically of the crossmodal correspondence between colours and basic tastes. That said, it is worth noting that the affective account has recently gained traction as a plausible explanation for the crossmodal correspondence between colours and both fragrances [48] and music [39]. Further investigation of the affective mediation account could presumably utilize a version of the clever experimentation introduced recently by Palmer et al. [39]. ${ }^{16}$

The key question here, then, is which account (or accounts) provides the best explanation for the results that have been published to date? Looking back over the literature, the explanation that most writers have reached for when trying to explain the crossmodal correspondence between colour and taste is that it reflects the internalization of the statistical regularities of the environment. So, for example, according to Watson [72]: "As true scavengers, we went looking for a wide variety of foods. These had certain characteristics in common which helped protomen find and recognize them and which still determine our choice of food today. Color is one of the most obvious. Ripe fruits are usually some shade of red or orange, roots and shoots are yellowish, nuts and edible animals are often brown. All these are warm colors that would have been distinctive against the green of foliage or grass. We still seek them out and tend to avoid the cold colours." Elsewhere, Koch and Koch [28] tentatively suggest that: "the relationship between color and taste may reflect only the frequency with which certain colors and foods or drinks have been paired."17

Indeed, one suggestion that has been made by a number of researchers is that the association of green and red to sour and sweet, respectively, comes from our brain's having picked up on the environmental regularity that many fruits do indeed transition from green, unripe, and sour through to ripe, red, and sweet (e.g. [72]). However, while this kind of account may work for the mapping of the sour and sweet tastes to colours, one can question the generalizability of this kind of explanation for the other basic tastes.

Indeed, according to Maga [31]: "numerous foods of varying color can be characterized as tasting salty, examples would be pretzels (brown), potato chips (yellow), popcorn (white), olives (green, black), and pickles (green)."18 According to Maga, then, a straightforward statistical account fails to do the work here. ${ }^{19}$ Presumably, it is the intuitive plausibility of the statistical account that explains its widespread and seemingly uncritical, acceptance by the majority of those working in this area. However, it needs to be remembered that until someone conducts a thorough analysis of the natural scene statistics as far as food colours and the tastes that are associated with them is concerned, it should be treated as little more than a plausible, and we admit intuitively pleasing, but ultimately yet to be validated assertion (see [1] on the danger of evolutionary psychology's 'just-so stories'). After all, if the association between salt and white comes from the crystalline substance most of us have in our kitchens, one might ask why sweet should not also be white, since sucrose, a major source of sweetness in our diet, is also 
commonly seen in crystals of that colour? Of course, it might be argued that the red, ripe, sweet association trumps the white sugar crystals account.

A possible semantic underpinning to the crossmodal correspondence between basic tastes and colours remains to be explored. Introspection might suggest that taste words are not commonly used to describe colours (at least not in the English language). ${ }^{20}$ Indeed, early analyses of various language corpora suggested that the use of taste words to describe colours would be more frequent, but that the use of colour words to characterize tastes was prevented by the directionality of the transfer of adjectives (see [74]) - if this claim was true, then linguistic habits could not account for the bi-directionality of the mappings. Such a conclusion will most likely have to be revised, though, given the results of Werning et al.'s [73] systematic study. They presented German speakers with all possible combinations of adjectives and showed that expressions applying olfactory and gustatory adjectives to colours were as easy to understand as those where colours were used to characterize smells and tastes. The bi-directionality of linguistic mappings therefore might serve to re-open the debate concerning the validity of the semantic hypothesis.

Finally, it is perhaps worth noting that, at least as far as we are aware, no one has offered a structural account of the correspondence between colour and basic taste. The same is not true of the relation between brightness and intensity of taste, which might, presumably, be explained by a common coding of stimulus intensity.

\section{Utilizing the crossmodal correspondence between colour and taste}

While theoretical models of the underlying mechanism(s) that best account for taste-colour correspondences are still being refined, putting these research findings to use has started to bring new insights into their perceptual and evaluative consequences. For example, one chef who has incorporated these results into the design of the dishes he serves is Jozef Youssef (https://kitchen-theory.com/). At a series of dining events running in Maida Vale, London, in early 2015, an amuse bouche was served that was named simply: "Sweet, sour, salty and bitter" (see Fig. 5a). The challenge for the diner, though, was to decide which colour corresponds to which taste.

We recently conducted a study on a group of 69 MBA students (21 females, 41 males, the remaining participants not specifying their age, mean age $=29.1$ years, $\mathrm{SD}=3.5$ ) from Oxford University's Saïd Business School to see how easy people would find this crossmodal matching task. ${ }^{21}$ The studies reported here were reviewed and approved by the Central University Research Ethics Committee (CUREC) of the University of Oxford. The data collection was conducted in accordance with the Declaration of Helsinki, and informed consent was obtained from all participants in both offline and online settings. The data from two of the participants was excluded from the analysis as they failed to follow the instructions (reporting the same taste for more than one colour). A Pearson's chi-square performed on the association between the taste responses and the coloured amuse bouches revealed a significant association between the two, $\chi^{2}=140.597, d f=9, p<.001$, Cramer's $\mathrm{V}=.418, p<.001$. A summary of the pairwise comparisons is presented in Table 3. The results are clearly non-random with a little over half of the participants $(52.24 \%)$ correctly decoding the chef's intentions (see Fig. 5b).

Looking at Fig. 5a, it is obvious that a number of factors are varying all at once here: colour, certainly, but also the presence vs. absence of a garnish. While an argument can perhaps be made that this is an essentially unavoidable element of actual culinary delivery, such uncontrolled variation in one's stimuli clearly fails to satisfy experimental standards. We therefore decided to repeat the matching experiment, but now using unadorned visual colour stimuli with the aim of extending and replicating the results of our offline experiment, online. The online study included a group of 104 participants $(35$ females, mean age $=34$ years, $\mathrm{SD}=12)$. The participants were presented with the stimuli shown in Fig. 5c and separately with those shown in Fig. 6. The order in which the two sets of stimuli were presented was randomized across participants. Furthermore, the positioning of each of the four or five stimuli was also randomized from one participant to the next. The online participants had to select the taste word that they felt best matched each of the stimuli. The results (see Fig. 5d) were analysed using a Pearson's chi-square analysis. Once again, a significant association was revealed between the basic tastes and the colours of the amuse bouche, $\chi^{2}=626.000, d f=9, p<.001$, Cramer's V $=.708, p<.001$.

The results revealed that, overall, $77.64 \%$ of the participants got all of the pairings correct (or, better said, decoded the chef's intentions). The fact that not everyone got the pairings $100 \%$ correct is interesting in its own right. First, one might question whether the specific hue of the colours was quite right. The descriptor green, or red, obviously covers a number of shades, and the crossmodal correspondence studies that have been reported to date (see the "Crossmodal correspondences between colour and taste words: the empirical evidence" section) have not gone beyond either the name of a colour, or else selected a particular shade. A summary of the pairwise comparisons is presented in Table 3. Note that, in contrast to the results of the offline experiment, the intended colour/taste associations were reflected in the matchings of most of the participants. 


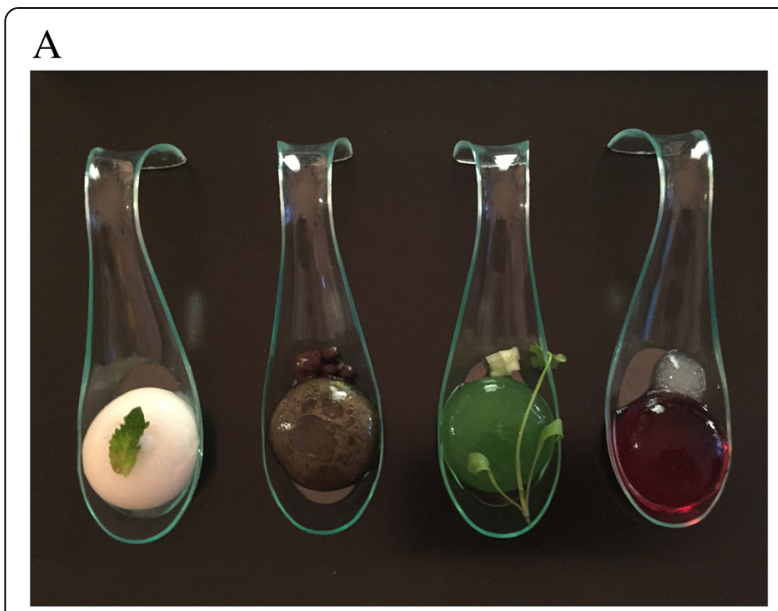

C

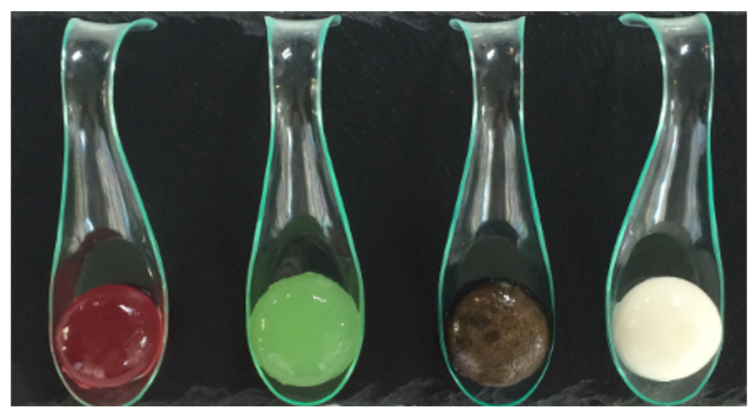

B

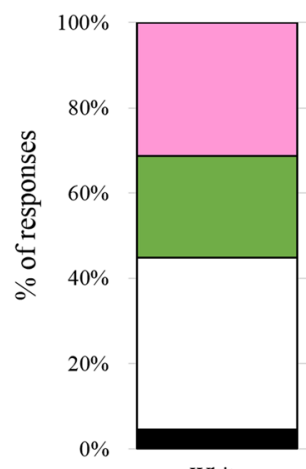

White
—Bitter 口Salty $\square$ Sour $\square$ Sweet

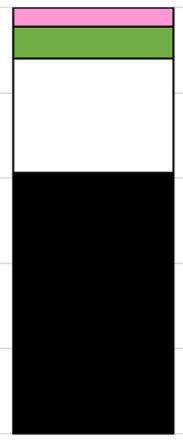

Black

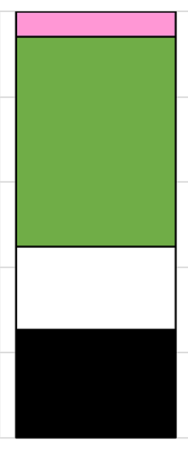

Green

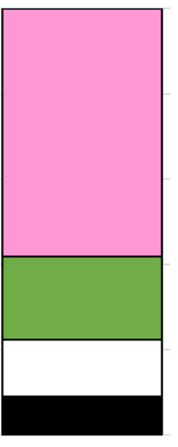

Red

Colour

D

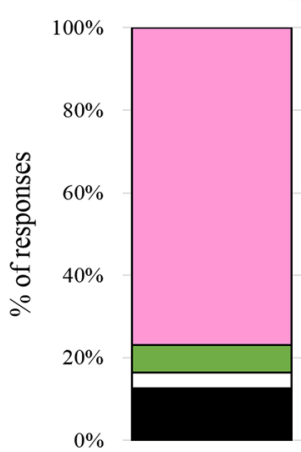

Red
घBitter $\square$ Salty $\square$ Sour $\square$ Sweet

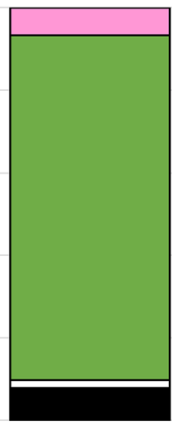

Green

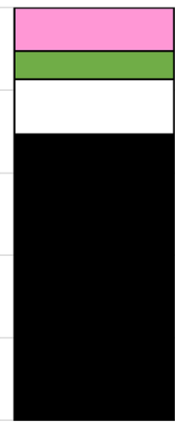

Black

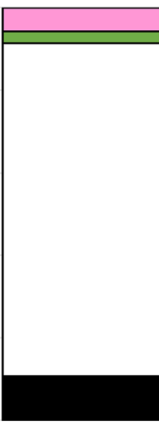

White

Colour

Fig. 5 a Salty, bitter, sour, and sweet, the amuse bouches served at Synaesthesia by Kitchen Theory (see https://kitchen-theory.com/). The spoons are brought to the table in a random arrangement, and it is the diner's job to sort the tastes by means of colour. The spoons in the figure have been arranged in the intended order as implied by the name (from left to right). This dish was inspired by the latest cross-cultural research demonstrating the robust crossmodal correspondences that exist between colour and taste (see [71]). These stimuli were shown to the participants in the offline study. $\mathbf{b}$ Results of the offline study in which 69 participants viewed the amuse bouche shown in $\mathbf{a}$ and had to try and match the appropriate taste with the matching coloured spoon. c Simplified amuse bouches (garnish removed). These stimuli were shown online to the participants in the online study. $\mathbf{d}$ Results of the online study in which participants viewed the amuse bouche shown in c online and had to try and match the appropriate taste with the matching coloured spoon

Table 3 Frequencies and pairwise comparisons from offline and online tests of people's ability to correctly associate the coloured amuse bouche shown in Fig. 5a, c with one of the four basic tastes

\begin{tabular}{|c|c|c|c|c|c|c|c|c|c|c|}
\hline \multirow[t]{2}{*}{ Colour } & \multicolumn{4}{|c|}{ Offline } & \multirow[t]{2}{*}{$n$} & \multicolumn{4}{|c|}{ Online } & \multirow[t]{2}{*}{$n$} \\
\hline & Bitter & Salty & Sour & Sweet & & Bitter & Salty & Sour & Sweet & \\
\hline Black & $41_{a}$ & $18_{\mathrm{b}}$ & $5 c$ & $3 c$ & 67 & $72 a$ & $14_{b}$ & $7 \mathrm{~b}$ & $11_{\mathrm{b}}$ & 104 \\
\hline Green & $17 \mathrm{a}$ & $13_{\mathrm{a}, \mathrm{b}}$ & $33_{c}$ & $4_{b}$ & & $8 a$ & $2 a$ & $87_{b}$ & $7 a$ & \\
\hline Red & $\sigma_{a}$ & $9_{a}$ & $13_{a}$ & $39_{b}$ & & $13 a$ & $4 a$ & $7 \mathrm{a}$ & $80_{b}$ & \\
\hline White & $3 a$ & $27_{b}$ & $16_{b}$ & $21_{b}$ & & $11_{a}$ & $84_{b}$ & $3 a$ & $\sigma_{a}$ & \\
\hline
\end{tabular}

The values in bold indicate the most frequently selected taste. Each subscript letter denotes a subset of colour categories whose proportions do not differ significantly from each other at the .05 level reading across a row
In summary, the results of these two experiments demonstrate that people are far better than chance at identifying the intended taste of each of chef Youssef's amuse bouche. However, the absence of perfect agreement, which will not surprise the psychologists, can be a problem when it comes to an actual dish, which should presumably work for everyone ? $^{22}$ Looking back at Table 2, it can be seen that salty is not uniquely matched with white, but also with blue. Similarly, the sour taste appears to be associated with green for some people but with yellow for others. And while many people match sweet with red, a not insubstantial number of people chose pink when that option was offered. Finally, both brown/black and violet/purple appear to be associated with the bitter taste. Such observations lead to the suggestion that if both colours were combined in each amuse bouche, people might would do even better 


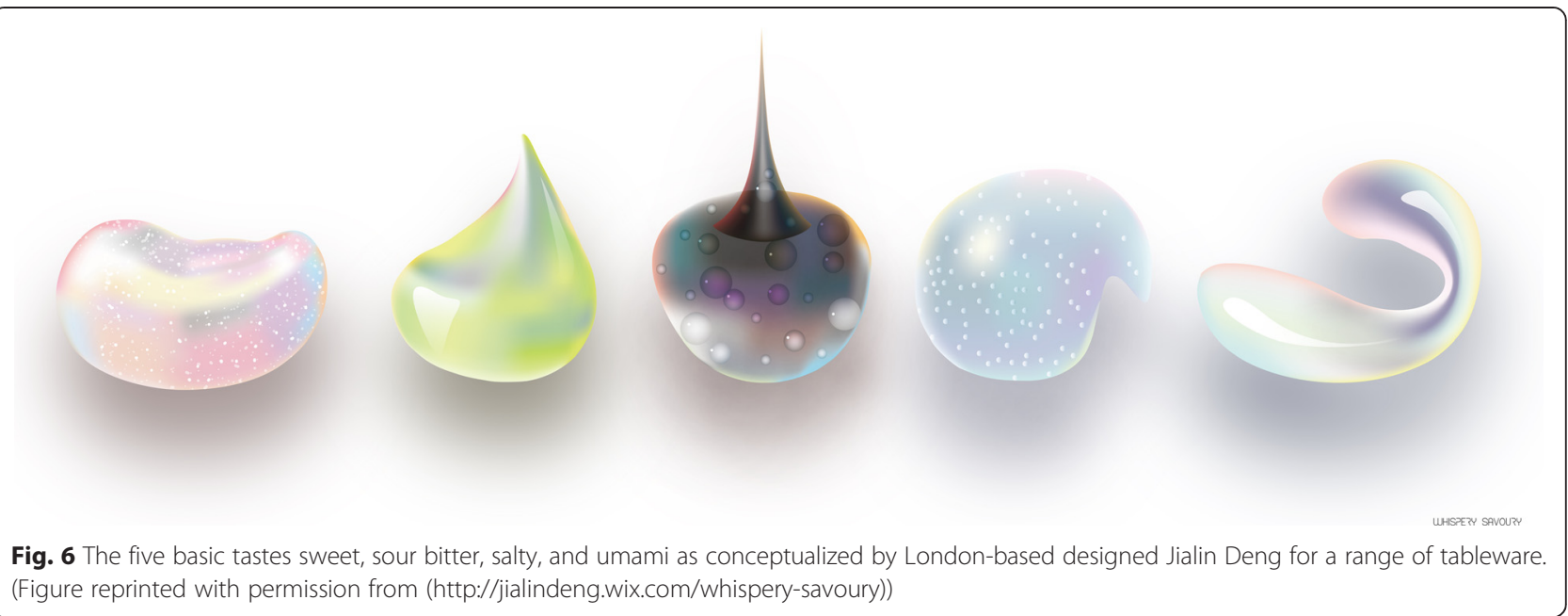

in terms of decoding the chef's intentions. ${ }^{23}$ What would happen, for instance, if the white amuse bouche were to be served on a blue spoon, the green amuse bouche on a yellow spoon, the red one on a pink spoon, and the browny/black one on a spoon of violet/purple colour? $^{24}$

Is this, the use of crossmodal correspondences to guide the presentation of a dish, anything more than a fad one might ask? Well, only time will tell. But already we have seen another chef Xavier Gomez, from Porto Allegre in Brazil, serving a version of this dish to the diners at a couple of dining events that were held recently (see http://xavier260.com/).

\section{Tasty plateware}

Another individual who is using the insights established by the scientific research is Jialin Deng. Coming from a design background, she has created a set of stimuli (prototypes for plateware that exist, thus far, only digitally) that she hopes that people will associate with one of the five basic tastes (see Fig. 6). We have conducted both offline (using the same group of students at the Said Business School, the data of two additional participants was excluded from the analysis for the same reasons as mentioned earlier) and online versions of the study (conducted at the same time as the other online study mentioned earlier). The results revealed that, overall, $54.15 \%$ of the participants in the offline study and $46.15 \%$ in the online study agreed with the intentions of the designer (see Fig. 7a, b, respectively). Pearson's chisquares revealed a significant association between the different designs and the taste words for both the offline, $X^{2}=271.077, d f=16, p<.001$, Cramer's $\mathrm{V}=.457$, $p<.001$, and online study, $x^{2}=287.500, d f=16$, $p<.001$, Cramer's V $=.372, p<.001$. A summary of the pairwise comparisons is shown in Table 4. (Note here that directly comparing these results with chef Jozef Youssef's espherified spoons is difficult given the inclusion of the fifth taste, umami, in Deng's plateware designs). ${ }^{25}$

\section{Tasty paint colours}

A third real-world example of the use of crossmodal correspondences between colour and taste is much further from the world of food. Boss, a Belgian paint company, has been working with a group of top chefs, including chocolatier Dominique Persoone to match their range of paint colours to basic tastes. Now, it is unclear from the publicity that accompanied this project (see [64]) whether the colour-taste mapping was based on the intuitions of the chefs involved, or perhaps the demands of the marketing team. That said, the correspondences bear an uncanny resemblance to those identified by Heller [24], as summarized in Table 2. Hence, it would appear that this represents a third case in which the crossmodal matches between colour and taste have been based on the crossmodal correspondences exhibited by a large group of participants, rather than on the idiosyncratic matches reported by a chromatic gustation synaesthete.

\section{Conclusions}

Traditionally, matching colours to tastes has been seen as a creative exercise, driven by the idiosyncratic inspiration of the designers or borrowed from those synaesthetes with the rare condition known as chromatic gustation. Increasingly, though, such designs are being based on the results derived from the science laboratory and online research. Indeed, the results of both online and in-lab tests have revealed that the majority of people match the taste of salt with white and blue, sweetness with red and pink, while sourness is associated with green and yellow, and bitterness with browny-black and violet/ purple. Importantly, there is good evidence to suggest that these crossmodal correspondences are consistent 

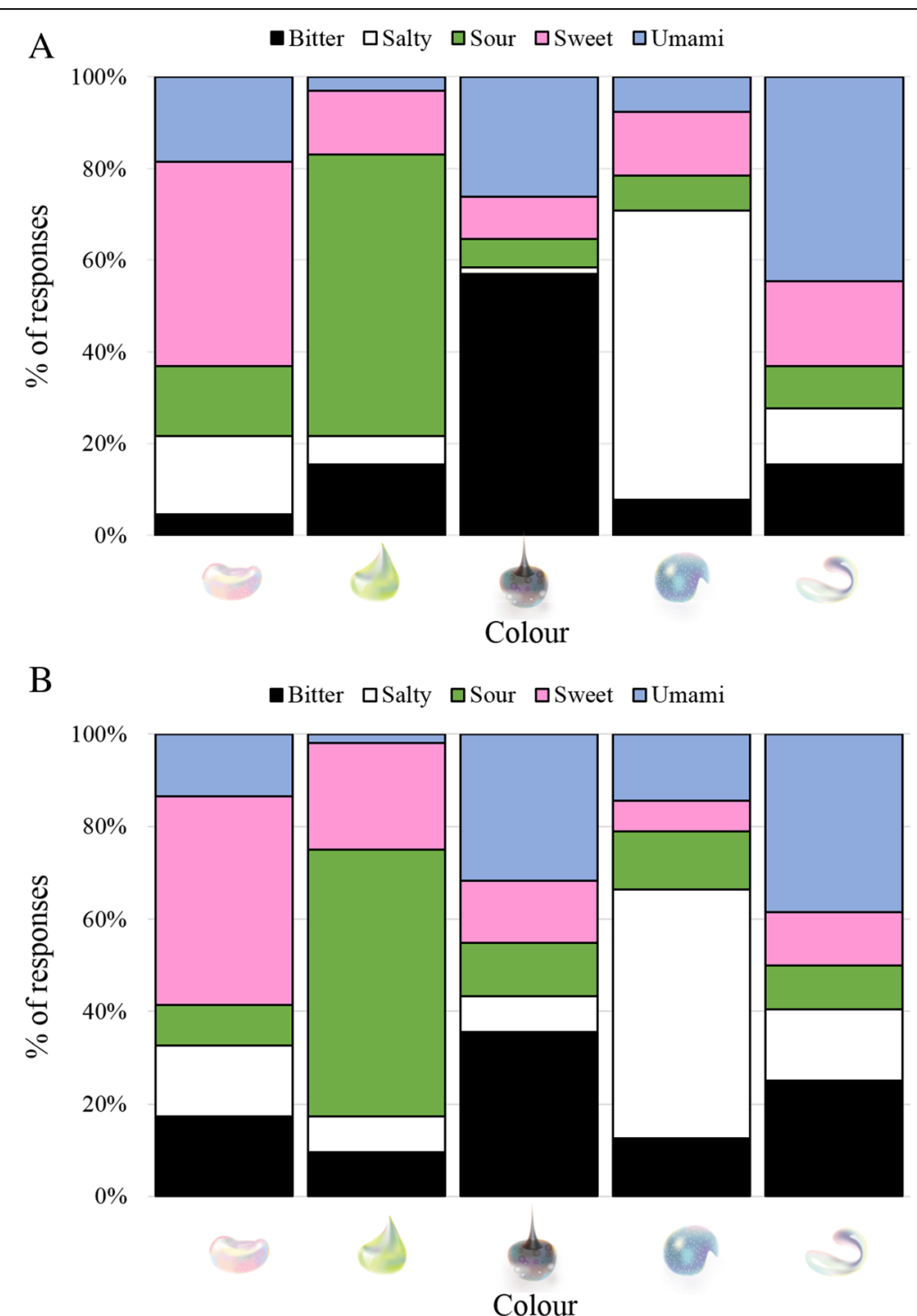

Fig. 7 Results of the offline (a) and online (b) studies in which the five stimuli shown in Fig. 6 were presented to participants who had to associate each visual stimulus with one of the five basic tastes

Table 4 Frequencies and pairwise comparisons from offline and online tests of people's ability to correctly associate the colourful plateware designs shown in Fig. 7 with one of the five basic tastes

\begin{tabular}{|c|c|c|c|c|c|c|c|c|c|c|c|c|}
\hline \multirow[t]{2}{*}{ Colour } & \multicolumn{6}{|c|}{ Offline } & \multicolumn{6}{|l|}{ Online } \\
\hline & Bitter & Salty & Sour & Sweet & Umami & $n$ & Bitter & Salty & Sour & Sweet & Umami & $n$ \\
\hline Black & $37 a$ & $1_{\mathrm{b}}$ & $4_{b}$ & $\sigma_{b, c}$ & $17_{c}$ & 65 & $37 a$ & $8 b$ & $12 b$ & $14 b$ & $33 a$ & 104 \\
\hline Green & $10_{a}$ & $4 a$ & $40_{b}$ & $9_{a}$ & $2 a$ & & $10 a, b, c$ & $8 c$ & $60 d$ & $24 b$ & $2 a, c$ & \\
\hline Pink & $3 a$ & $11_{a}$ & $10_{a}$ & $29_{b}$ & $12 \mathrm{a}$ & & $18 a$ & $16 a$ & $9 a$ & $47 b$ & $14 a$ & \\
\hline Tilted & $10_{a}$ & $8 a$ & $6_{a}$ & $12 a$ & $29_{b}$ & & $26 a, b$ & $16 b, c$ & $10 c$ & $12 b, c$ & $40 a$ & \\
\hline White & $5 a$ & $41_{b}$ & $5 a$ & $9 a$ & $5 a$ & & $13 a$ & $56 \mathrm{~b}$ & $13 a$ & $7 a$ & $15 a$ & \\
\hline
\end{tabular}

The values in bold indicate the most frequently selected taste. Each subscript letter denotes a subset of colour categories whose proportions do not differ significantly from each other at the .05 level when reading across a row 
across different cultures and through time (at least over the last three decades), despite the wide cultural differences in the use of colours across cuisines ([76], see also [70]). These results therefore suggest that colour-taste correspondences may be in some sense 'more primitive' than certain other correspondences that research has shown to be more culturally relative [4]. While the underlying explanation for such crossmodal correspondences between tastes (or taste words) and colours (or colour descriptors) has yet to be thoroughly worked out, it is nonetheless clear that such regular mappings should not be confused with the idiosyncratic conscious associations occasionally reported by those rare individuals with chromatic gustation. While losing the seductive label of synaesthesia might, at first sight, seem like a loss, the present review has hopefully made clear that it can actually be seen as opening up the possibility of delivering on colour-taste matches that can be enjoyed by everyone.

\section{Endnotes}

${ }^{1}$ In a fictional story entitled "An Abstract Art" (first published in English in 1969), Borges and Bioy-Casares ([2], p. 72) describe a Parisian restaurant Les Cinq Saveurs opened by Ishmael Querido at the turn of the nineteenth century. (A restaurant with the same name, situated around the corner from the Panthéon des Invalides, is still there to this day). The authors write that: "the druggist Payot...began furnishing Querido each week with twelve hundred identical pyramids, each an inch high and each affording the palate one of the now celebrated five tastes-sour, insipid, salty, sweet, and bitter. A veteran of these early campaigns had assured us that at first the pyramids were greyish and translucent and that later on, to make things easier, they were endowed with the five well-known colors, white, black, yellow, red, and blue." However, while the different tasting pyramids had different colours, Borges and BioyCasares do not reveal what the mapping between taste and colour was, or even whether it was consistent.

${ }^{2}$ Others who have tried to convey the taste or flavour of their product through the abstract use of colour include the spice company Schwartz who used exploding bags of colour(-ed spices) in one of their recent advertising campaigns for their Flavour Pods range (see [16]).

${ }^{3}$ Amuse bouche is the name given to a single, bite-sized hors d'euvre. It is different from a starter (or appetizer) in that it is not ordered from a menu by the diner, but rather is chosen by the chef and is complementary.

${ }^{4}$ Nevertheless, it is clear that some of the participants reported that none of the six colours was associated with particular tastes.

${ }^{5}$ O'Mahony's [35] participants reported that the matching tasks that they had been asked to perform became subjectively easier across the three testing sessions.
${ }^{6}$ In the future, it would be intriguing to test a group of experts on this, such as those working in the food industry, or perhaps designers to see whether they might have a more confident sense of how other people would respond on tasks such as these.

${ }^{7}$ To address this problem, Wan et al. [71] directed any participants who were uncertain to the Wikipedia page for an explanation of umami (see http://en.wikipedia.org/ wiki/Umami).

${ }^{8}$ Note here, though, that using actual tastants does have the advantage that stimulus intensity can be varied parametrically ([67]).

${ }^{9}$ Echoing the cases of audition coloree which started the interest in synaesthesia $[18,26]$.

${ }^{10}$ Though, interestingly, these concurrent colours did not give rise to any colour aftereffects, as would have been expected had colour stimuli actually been presented.

${ }^{11}$ Sometimes in these early studies, it can also be rather difficult to ascertain whether it was actually a basic taste that induced the colour concurrent reported by the synaesthete, or the aroma, texture, or flavour of the food instead. Certainly, in the related case of shape-taste synaesthesia, it has been convincingly demonstrated that pure tastants (in solution) can trigger reliable shape concurrents (e.g. see [7, 8], see also [57]).

${ }^{12}$ The only exception here, according to Downey [15], being odours that triggered a taste. Sadly, the details given in the study are not sufficient to figure out whether these were so-called sweet smells such as vanilla or strawberry [61].

${ }^{13}$ In fact, the structural account might fundamentally reflect the statistics of the environment. Bear in mind here the fact that observers have been shown to internalize novel correlations in the environment after fairly brief exposure.

${ }^{14}$ Of course, the semantic correspondences might well build on, or reflect, the statistical associations that are present in the environment.

${ }^{15}$ Note here that it is presumably possible to think of the availability heuristic as also underpinning the semantic account!

${ }^{16}$ Interestingly, a link between taste and emotion is also embedded in the Chinese language. Take, the fourcharacter word "Suan Tian Ku La" (corresponding to sourness, sweetness, bitterness, and spiciness, respectively) which is often used to refer to all kinds of life experiences, including those that are both happy and painful.

${ }^{17}$ Distinguishing between the statistical account and the use of the availability heuristic is no simple task. Perhaps one could try manipulating certain of the factors (such as recency and/or saliency) that have been shown to influence people's decision-making judgments when based on the availability heuristic. The prediction here if availability is the root cause of the correspondence is 
that it should be susceptible to any recently primed taste stimuli. One might, for example, want to check whether the strength of the red/pink-sweet mapping can be changed simply by showing participants sweet white foods, such as vanilla ice cream and white confectionary, or crystalline sugar prior to asking them to pick a colour to match a sweet taste.

${ }^{18}$ As mentioned already, on top of the crossmodal correspondence between basic tastes and particular colours, one might also consider the tendency for foods and their packaging to present more saturated colours when the taste of the product itself is more intense. According to some, this crossmodal matching of stimulus intensity could provide an example of one of the few structural correspondences that have been suggested to date $[54,60]$.

${ }^{19}$ Maga [31] was seemingly forced into this line of reasoning by the fact that his results revealed no effect of colouring on the threshold for salt taste. However, a quick look at his procedure soon reveals that this may simply reflect the fact that neither white nor blue, the two colours that the research reviewed in the "Crossmodal correspondences between colour and taste words: the empirical evidence" section (see Table 2) showed were associated with salt, were used in Maga's study. Instead, he just compared solutions that were clear to those that were red, green, or yellow.

${ }^{20}$ There are, though, associations between colour and taste terms in traditional Chinese philosophy. Most importantly, the five-element framework explains everything in terms of the five elements-wood, fire, earth, metal, and water. According to this philosophy, there might be spiritual and sensorial correspondences between these five elements to senses, colours, emotions, and so on (e.g. [34]). Therefore, one might consider whether the existence of such a system might create a link between a given colour and a certain taste when they correspond to the same "element." In the modern Chinese language, certain phrases link colours with tastes, such as red and spicy. No wonder, then, that some Chinese associate red with spicy (Zhou et al. [76]; also see [51], for a similar pattern shown by Westerners). Obviously, cross-cultural research mapping colour to taste should, wherever possible, take account of such language-specific peculiarities.

${ }^{21}$ Note that the participants also performed a second matching task, the results of which are reported later.

${ }^{22}$ Of course, one might also argue that some degree of disagreement between people can also be desirable, at least in the context of Youssef's Synaesthesia dinner, where the idea is that the 14 diners, all sitting at a single long table, will discuss with their dinner companions, what is going on, and why they made the choices that they did.
${ }^{23}$ Perhaps colours need to be expressed in a dish in the same ratio as observed in Table 2?

${ }^{24}$ This also links with idea of selling complementary colours, as seen in the paint marketing example [64], and also to literature on spoon colour [22].

${ }^{25}$ One interesting point to note here is that the shapes with points oriented upward. Given that bitterness, and to a lesser extent, sourness are both associated with danger-poison in the former case, and overripe fruit in the latter-one might imagine inverting the stimuli so that the point is oriented downward (another signal that the human brain appears to treat as representing danger; [50]).

\section{Competing interests}

The authors declare that they have no competing interests.

\section{Authors' contributions}

$C S, X W, C V, J Y, J D, A W$, and $O D$ all contributed to the writing of this paper. Data collection was performed by CS, AW, CV, JY, and XW. Statistical analysis was performed by AW, XW, and CV. OD helped with the interpretation and contextualization of the results. All of the authors read and approved the final version of the manuscript.

\section{Acknowledgements}

CS and OD would like to acknowledge the AHRC Rethinking the Senses grant (AH/L007053/1). Written informed consent was obtained for publication of this manuscript and accompanying images.

\section{Author details}

${ }^{1}$ Crossmodal Research Laboratory, Oxford University, Oxford, UK. ${ }^{2} T$ singhua University, Beijing, China. ${ }^{3}$ Xperiment, Lausanne, Switzerland. ${ }^{4}$ Design, London, UK. ${ }^{5}$ Kitchen Theory, London, UK. ${ }^{6}$ Centre for the Study of the Senses, School of Advanced Study, University of London, London, UK. ${ }^{7}$ Department of Experimental Psychology, University of Oxford, Oxford OX1 3UD, UK.

Received: 26 March 2015 Accepted: 11 June 2015 Published online: 08 July 2015

\section{References}

1. Baggini J. The pig that wants to be eaten and 99 other thought experiments. London, UK: Granta; 2005.

2. Borges JL, Bioy-Casares A. An abstract art. In: Golden L, editor. A literary feast. New York, NY: The Atlantic Monthly Press; 1993. p. 70-3.

3. Bredle WLP, Tan HSG, Wendin K. A comparative study on facially expressed emotions in response to basic tastes. Chemosensory Perception. 2014;7:1-9.

4. Bremner A, Caparos S, Davidoff J, de Fockert J, Linnell K, Spence C. Bouba and Kiki in Namibia? A remote culture make similar shape-sound matches, but different shape-taste matches to Westerners. Cognition. 2013;126:165-72.

5. Collier GL. Affective synaesthesia: extracting emotion space from simple perceptual stimuli. Motivation and Emotion. 1996:20:1-32.

6. Collins M. A case of synaesthesia. Journal of General Psychology. 1929;2:12-27.

7. Cytowic RE. The man who tasted shapes. USA: G. P. Putnam's Sons; 1993.

8. Cytowic RE, Wood FB. Synaesthesia II: psychophysical relations in the synaesthesia of geometrically shaped taste and colored hearing. Brain Cogn. 1982;1:36-49.

9. Day S. Some demographic and socio-cultural aspects of synesthesia. In: Robertson LC, Sagiv N, editors. Synesthesia: perspectives from cognitive neuroscience. New York, NY: Oxford University Press; 2005. p. 11-33.

10. Déjerine M. Paris: chromatic gustation. Lancet. 1892;2:1253.

11. Demattè ML, Sanabria D, Spence C. Cross-modal associations between odors and colors. Chem Senses. 2006;31:531-8.

12. Deroy O, Crisinel A-S, Spence C. Crossmodal correspondences between odors and contingent features: odors, musical notes, and geometrical shapes. Psychon Bull Rev. 2013;20:878-96. 
13. Deroy O, Spence C. Why we are not all synesthetes (not even weakly so). Psychon Bull Rev. 2013;20:643-64.

14. Deroy $\mathrm{O}$, Spence $C$. Are we all born synaesthetic? Examining the neonatal synaesthesia hypothesis. Neurosc Biobehav Rev. 2013;37:1240-53.

15. Downey JE. A case of colored gustation. American Journal of Psychology. 1911:22:528-39.

16. Dunne C. Watching these spice bags explode is the most satisfying thing you'll do all day. 2014. Downloaded from http://www.fastcodesign.com/ 3024922/watching-these-spice-bags-explode-is-the-most-satisfying-thingyoull-do-today on 01/03/2015.

17. Ernst MO. Learning to integrate arbitrary signals from vision and touch. J Vis. 2007;7(5/7):1-14.

18. Flournoy T. Des phénomènes de synopsie (audition colorée) photismes, schèmes visuels, personnifications. Paris: Alcan; 1893.

19. Garber Jr LL, Hyatt EM, Boya ÜÖ. The mediating effects of the appearance of nondurable consumer goods and their packaging on consumer behavior. In: Schifferstein HNJ, Hekkert P, editors. Product experience. London, UK: Elsevier; 2008. p. 581-602.

20. Grimes W. First, a little something from the chef . . . Very, very little. The New York Times, July 22. 1998. Downloaded from http://www.nytimes.com/ 1998/07/22/dining/first-a-little-something-from-the-chef-very-very-little. html?pagewanted=all\&src=pm.

21. Grossenbacher PG, Lovelace CT. Mechanisms of synesthesia: cognitive and physiological constraints. Trends Cogn Sci. 2001;5:36-41.

22. Harrar V, Spence C. The taste of cutlery. Flavour. 2013;2:21.

23. Haverkamp M. Synesthetic design: handbook for a multisensory approach. Basel: Birkhäuser; 2014

24. Heller E. Wie farben wirken. Farbpsychologie, farbsymbolik, kreative farbgestaltung [How colour works. Colour psychology, colour symbolism, working creatively with colour]. Reinbek bei Hamburg. 1999

25. Henrich J, Heine SJ, Norenzayan A. The weirdest people in the world? Behav Brain Sci. 2010;33:61-135.

26. Jewanski J, Day SA, Ward J. A colorful albino: the first documented case of synaesthesia, by Georg Tobias Ludwig Sachs in 1812. J Hist Neurosci. 2009;18:293-303.

27. Kahneman D, Tversky A. On the psychology of prediction. Psychol Rev. 1973;80:237-51.

28. Koch C, Koch EC. Preconceptions of taste based on color. J Psychol Interdiscipl Appl. 2003;137:233-42.

29. Koriat A. Subjective confidence in one's answers: the consensuality principle J Exp Psychol Learn Mem Cogn. 2008;34:945-59.

30. Lewkowicz DJ, Turkewitz G. Cross-modal equivalence in early infancy: auditory-visual intensity matching. Dev Psychol. 1980;16:597-607.

31. Maga JA. Influence of color on taste thresholds. Chem Senses Flavor. 1974;1:115-9.

32. Marks LE. On colored-hearing synesthesia: cross-modal translations of sensory dimensions. Psychol Bull. 1975;82:303-31.

33. Martino G, Marks LE. Perceptual and linguistic interactions in speeded classification: tests of the semantic coding hypothesis. Perception. 1999;28:903-23.

34. Matsumoto K, Birch S. Five elements and ten stems. Higganum, CT: Paragon; 1983.

35. O'Mahony M. Gustatory responses to nongustatory stimuli. Perception. 1983;12:627-33.

36. O'Mahony M, Goldenberg M, Stedmon J, Alford J. Confusion in the use of the taste adjectives 'sour' and 'bitter'. Chem Senses Flavour. 1979;4:301-18.

37. Ou LC, Luo MR, Woodcock A, Wright A. A study of colour emotion and colour preference. Part I: colour emotions for single colours. Color Res App. 2004;29:232-40.

38. Ou LC, Luo MR, Woodcock A, Wright A. A study of colour emotion and colour preference. Part II: colour emotions for two-colour combinations. Color Res App. 2004;29:292-8.

39. Palmer SE, Schloss KB, Xu Z, Prado-León LR. Music-color associations are mediated by emotion. Proc Nat Acad Sci USA. 2013;110:8836-41.

40. Parise CV, Knorre K, Ernst MO. Natural auditory scene statistics shapes human spatial hearing. Proc Nat Acad Sci USA. 2014;111:6104-8.

41. Parise CV, Spence C. Audiovisual crossmodal correspondences. In: Simner J, Hubbard EM, editors. The Oxford handbook of synesthesia. Oxford: Oxford University Press; 2013. p. 790-815.

42. Peirce CS. Some consequences of four incapacities. J Speculative Psychol. 1868;2:140-57.
43. Pollard P. Human reasoning: some possible effects of availability. Cognition. 1982;12:65-96.

44. Prescott J, Laing D, Bell G, Yoshida M, Gillmore R, Allen S, et al. Hedonic responses to taste solutions: a cross-cultural study of Japanese and Australians. Chem Senses. 1992;17:801-9.

45. Ramachandran VS, Hubbard EM. Hearing colors, tasting shapes. Sci Am. 2003;288(May):43-9.

46. Reardon P, Bushnell EW. Infants' sensitivity to arbitrary pairings of color and taste. Infant Behav Dev. 1988;11:245-50.

47. Rosenstein D, Oster $\mathrm{H}$. Differential facial responses to four basic tastes in newborns. Child Dev. 1988;59:1555-68.

48. Schifferstein HNJ, Tanudjaja I. Visualizing fragrances through colors: the mediating role of emotions. Perception. 2004;33:1249-66.

49. Shankar MU, Levitan C, Spence C. Grape expectations: the role of cognitive influences in color-flavor interactions. Consciousness Cogn. 2010;19:380-90.

50. Shen X, Wan X, Mu B, Spence C. Attentional capture by triangular shaped food. Food Qual Prefer. 2015;44:26-35.

51. Shermer DZ, Levitan CA. Red hot: the crossmodal effect of color intensity on piquancy. Multisensory Res. 2014;27:207-23.

52. Simmons DR. Colour and emotion. In: Biggam CP, Hough CA, Kay CJ, Simmons DR, editors. New directions in colour studies. USA: John Benjamins Publishing Company; 2011. p. 395-413.

53. Simner J, Cuskley C, Kirby S. What sound does that taste? Cross-modal mapping across gustation and audition. Perception. 2010;39:553-69.

54. Spence C. Crossmodal correspondences: a tutorial review. Atten Percept Psychophys. 2011;73:971-95.

55. Spence C. On the psychological impact of food colour. Flavour. 2015;4:21.

56. Spence C, Deroy O. Crossmodal mental imagery. In: Lacey S, Lawson R, editors. Multisensory imagery: theory and applications. New York, NY: Springer; 2013. p. 157-83.

57. Spence C, Deroy O. Tasting shapes: a review of four hypotheses. Theoria et Historia Scientiarum. 2013;10:207-38.

58. Spence C, Piqueras-Fiszman B. The perfect meal: the multisensory science of food and dining. Oxford, UK: Wiley-Blackwell; 2014

59. Steiner JE, Glaser D, Hawilo ME, Berridge KC. Comparative expression of hedonic impact: affective reactions to taste by human infants and other primates. Neurosci Biobehav Rev. 2001;25:53-74.

60. Stevens SS. Issues in psychophysical measurement. Psychol Rev. 1971;78:426-50.

61. Stevenson RJ, Boakes RA. Sweet and sour smells: learned synaesthesia between the senses of taste and smell. In: Calvert GA, Spence C, Stein BE, editors. The handbook of multisensory processing. Cambridge, MA: MIT Press; 2004. p. 69-83.

62. Stuckey B. Taste what you're missing: the passionate eater's guide to why good food tastes good. London: Free Press; 2012.

63. Stummerer S, Hablesreiter M. Food design XL. New York, NY: Springer; 2010.

64. Tastecolours. Colora 2015. Downloaded from http://www.colora.be/nl-BE/ Collecties/Tastecolours on 28/02/2015.

65. Tomasik-Krótki J, Strojny J. Scaling of sensory impressions. J Sensory Stud. 2008;23:251-66.

66. Velasco C, Salgado-Montejo A, Marmolejo-Ramos F, Spence C. Predictive packaging design: tasting shapes, typefaces, names, and sounds. Food Qual Prefer. 2014;34:88-95.

67. Velasco C, Woods A, Deroy O, Spence C. Hedonic mediation of the crossmodal correspondence between taste and shape. Food Qual Prefer. 2015;41:151-8

68. Velasco C, Woods A, Liu J, Spence J. Assessing the role of taste intensity and hedonics in taste-shape correspondences. Multisensory Res. In press.

69. Walker P. Cross-sensory correspondences and cross talk between dimensions of connotative meaning: visual angularity is hard, high-pitched, and bright. Atten Percept Psychophys. 2012;74:1792-809.

70. Wan X, Woods AT, Velasco C, Salgado-Montejo A, Spence C. Assessing the expectations associated with pharmaceutical pill colour and shape. Food Qual Prefer. In press.

71. Wan X, Woods AT, van den Bosch J, McKenzie KJ, Velasco C, Spence C. Cross-cultural differences in crossmodal correspondences between tastes and visual features. Front Psychol Cogn. 2014;5:1365.

72. Watson L. The omnivorous ape. New York, NY: Coward, McCann, \& Geohhegan; 1971.

73. Werning M, Fleischhauer J, Beseoglu $H$. The cognitive accessibility of synaesthetic metaphors. In: Proceedings of the Twenty-Eighth Annual 
Conference of the Cognitive Science Society. London, UK: Lawrence Erlbaum; 2006. p. 2365-70

74. Williams JM. Synesthetic adjectives: a possible law of semantic change. Language. 1976;52:461-78.

75. Woods AT, Poliakoff E, Lloyd DM, Dijksterhuis GB, Thomas A. Flavor expectation: the effect of assuming homogeneity on drink perception. Chemosens Percept. 2010;3:174-81.

76. Zhou X, Wan X, Mu B, Du D, Spence C. Crossmodal associations and subjective ratings of Asian noodles and the impact of the receptacle. Food Qual Prefer. 2015;41:141-50.

Submit your next manuscript to BioMed Central and take full advantage of:

- Convenient online submission

- Thorough peer review

- No space constraints or color figure charges

- Immediate publication on acceptance

- Inclusion in PubMed, CAS, Scopus and Google Scholar

- Research which is freely available for redistribution 